\title{
Intermittent Warming Affects Cell Wall Composition of 'Fantasia' Nectarines during Ripening and Storage
}

\author{
D.M. Dawson ${ }^{1}$ and C.B. Watkins ${ }^{2}$ \\ The Horticulture and Food Research Institute of New Zealand, Private Bag 92 169, Auckland, \\ New Zealand
}

L.D. Melton

Department of Food Science, University of Otago, P.O. Box 56, Dunedin, New Zealand

Additional index words. Prunus persica, softening

\begin{abstract}
Cell wall changes in 'Fantasia' nectarines [Prunus persica (L) Batsch var. nectarina (Ait) maxim] were determined after storage at $\mathrm{OC}$ with or without intermittent warming (at $20 \mathrm{C}$ at 2-week intervals) and after ripening. For comparison, fruit were examined at harvest and after ripening without storage. Fruit stored continuously at $0 \mathrm{C}$ for 6 weeks became mealy during ripening, whereas fruit subjected to intermittent warming ripened normally. Ripening immediately after harvest was associated with solubilization and subsequent depolymerization of pectic polymers and a net loss of galactosyl residues from the cell wall. No solubilization of pectic polymers from the cell wall occurred during storage of fruit at $0 \mathrm{C}$. Mealy fruit, ripened after continuous storage at $\mathrm{OC}$, showed only limited solubilization of pectins and depolymerization, high relative molecular weight $\left(M_{r}\right)$ polymers being predominant. During ripening after storage, pectic polymer solubilization was not as extensive in intermittently warmed fruit as in fruit undergoing normal ripening but solubilized polymers were depolymerized, low $M_{r}$ uronic acid-rich polymers becoming predominant. Intermittent warming of fruit resulted in significant softening during storage, alleviating the development of mealiness by promotion of cell wall changes associated with normal ripening.
\end{abstract}

Normal ripening of nectarines and peaches is characterized by loss of flesh firmness, a decrease in insoluble pectin, and an increase in soluble pectin (Ben-Arie and Lavee, 1971). Concomitantly the $M_{r}$ of soluble pectins decreases (Pressey et al., 1971). Loss of arabinosyl and galactosyl residues from the cell wall during ripening was reported by Gross and Sams (1984). Recently, we have shown that these events are coordinated with solubilization of high $\mathrm{M}_{\mathrm{r}}$ uronic acid-rich polymers from the cell wall and removal of galactan side chains from pectic polymers in the cell wall material (CWM), which occur during the initial 2 days of ripening (Dawson et al., 1992). The latter stages of ripening were characterized by the degradation of solubilized high $\mathrm{M}_{\mathrm{r}}$ pectins resulting in a decrease in molecular size (Dawson et al., 1992). Physiological measurements, such as cation exchange capacity and calcium uptake indicate that the ability of the nectarine tissue to bind calcium decreases significantly during ripening, suggesting that calcium binding sites are lost due to pectic solubilization (Dawson et al., 1993).

A physiological disorder known as mealiness or woolliness is found in nectarines and peaches during ripening after prolonged periods of cool storage (Ben-Arie and Lavee, 197 1). The affected fruit are lacking in juice and have a dry mealy texture, but otherwise appear to have ripened normally. Ben-Arie and Lavee (1971) attributed mealiness to the presence of insoluble low methoxy pectic substances of high $\mathrm{M}_{\mathrm{r}}$. Mealiness affects predominantly the pectic polymers, only limited pectic solubilization, and

Received for publication 17 Mar. 1995. Accepted for publication 12 June 1995. The cost of publishing this paper was defrayed in part by the payment of page charges. Under postal regulations, this paper therefore must be hereby marked advertisement solely to indicate this fact.

'Supported by a grant from the DSIR Biological Industries Group Fellowship. Also with the Univ. of Otago, New Zealand. To whom reprint requests should be addressed.

'Current address: Dept. of Fruit and Vegetable Science, Cornell Univ., Ithaca, NY 14853. removal of pectin side chains occurring in mealy fruit and polymers that were solubilized being not further degraded to lower $M_{r}$ species (Dawson et al., 1992; Lurie et al., 1994). Mealy fruit also show altered physiology from normally-ripened fruit. Furmanski and Buescher (1979) reported reduced internal conductivity of fruit during storage and in subsequently ripened (mealy) fruit which they interpreted as being the consequence of cation binding to enhanced levels of demethylated pectin. More recently, Harker and Maindonald (1994) used impedance measurements to show the electrical resistance was greater in the cell wall of mealy fruit than in those of normally ripened nectarines, Calcium-binding sites in the cell walls of mealy fruit during ripening do not decrease to the same extent as during normal ripening, as shown by cation exchange capacity and calcium uptake data, suggesting that less pectin is solubilized from the cell wall during mealy fruit ripening (Dawson et al., 1993).

Mealiness in stone fruit can be alleviated by intermittent warming, in which fruit are removed at regular intervals from storage at 0 or $1 \mathrm{C}$ and warmed to temperatures in the range 18 to 25C (Anderson, 1979; Anderson and Penney, 197.5; Ben-Arie et al., 1970; Lill, 1985). The mechanism by which mealiness is alleviated by intermittent warming is not clear. Buescher and Furmanski (1978) suggested that intermittent warming protected the capacity of fruit to produce adequate levels of pectinesterase and polygalacturonase during ripening. BenArie and Sonego (1980) observed that polygalacturonase activity in fruit warmed intermittently reached levels similar to those in normally-ripened fruit. They suggested that transfer of fruit to the higher temperatures within a critical period, before the inactivation of polygalacturonase, enabled resumption of enzyme activity resulting in dissolution of accumulated substrate, and normal ripening ensued. Pectinesterase activity was lower in intermittently warmed fruit than in fruit continuously stored at chilling temperatures (Ben-Arie and Sonego, 1980).

Cell wall analyses have provided a useful approach to understanding physiological and biochemical factors associated with 
the development of mealiness (Dawson et al., 1992; Lurie et al., 1994), and our objective here was to study the effect of alleviating mealiness by intermittent warming on fruit cell wall composition. We followed cell wall and pectic polymer compositional changes during storage, both with and without intermittent warming and of fruit ripened after storage.

\section{Materials and Methods}

Fruit and their measurements. 'Fantasia' nectarines were harvested from a commercial orchard in Hawkes Bay. Fruit were packed in single layer trays lined with polyliner. A harvest sample was taken and the remaining fruit were either ripened at $20 \mathrm{C}$ for 6 days or placed in storage at 0C. Two storage regimes were used: fruit were either stored continuously at $0 \mathrm{C}$ or subjected to warming at $20 \mathrm{C}$ for $48 \mathrm{~h}$ after 2 and 4 weeks at $0 \mathrm{C}$. At the end of the 48-h warming period, fruit were returned to storage at $0 \mathrm{C}$. Additional fruit samples were also ripened at 20C after 2, 4, and 6 weeks storage.

At each sampling time, ten fruit were taken at random from a tray of 25 fruit and used for measurement of flesh firmness and extractable juice content. Flesh firmness (N) was measured using a penetrometer (FT 011; Effegi, Italy) fitted with a 7-mm-diameter plunger, after the removal of a 1-mm thick disc of skin from the shoulder of the fruit. Extractable juice was measured using a modification of the cellular integrity test (Lill and Van Der Mespel, 1988). A 1-cm-diameter core, $5 \mathrm{~cm}$ long from the fruit mesocarp was inserted into a $2.5-\mathrm{ml}$ syringe barrel with a glass wool plug and centrifuged for $5 \mathrm{~min}$ at $5000 \times \mathrm{g}$, after which the extractable juice was weighed. The density of the juice was determined and the extractable juice expressed as $\mathrm{ml} / \mathrm{plug}$. The remaining 15 fruit were peeled, diced, frozen in liquid nitrogen, and stored at $-80 \mathrm{C}$ as a single composite sample until required for cell wall analysis.

Preparation and fractionation of the cell wall. CWM was extracted by grinding frozen fruit tissue in a cryomill at $-80 \mathrm{C}$ to produce a fine powder. The powder $(100 \mathrm{~g})$ was then homogenized in a blender with $250 \mathrm{ml}$ of 2 phenol : acetic acid : water (w/v/v) (PAW) for $4 \times 30 \mathrm{sec}$ and filtered through Miracloth. A further $125 \mathrm{ml}$ of PAW was added to the insoluble material which was then homogenized for $4 \times 30 \mathrm{sec}$ and filtered through Miracloth. The insoluble residue was twice washed with $100 \mathrm{ml}$ of cold distilled water. All supernatants were combined and lyophilized after dialysis (M cutoff 14000) against distilled water at 4C (PAW-soluble). The residue was dialyzed as above and lyophilized to give CWM. Yields represent the lyophilized material recovered from an initial $100 \mathrm{~g}$ of frozen powdered mesocarp. CWM (100 mg) was fractionated to yield CDTA- and $\mathrm{Na}_{2} \mathrm{CO}_{3}$-soluble pectic fractions, using the method of Jarvis (1982) as modified by Dawson et al. (1992), and an insoluble residue.

Cell wall and pectic polymer analyses. The size distribution of pectic and neutral polymers of PAW-soluble and fractionated soluble polymers from the CWM was determined by gel filtration chromatography as described by Dawson et al. (1992). Pectic polysaccharides were quantified as anhydrogalacturonic acid using the $m$ - hydroxydiphenyl method (Blumenkrantz and AsboeHansen, 1973). Reagents were made up as described by Kintner and Van Buren (1982). The anthrone method of Dische (1962) was used to quantify neutral sugars. Glucose was used as the standard. The monosaccharide composition of the PAW-soluble, CWM and fractions solubilized from the cell wall was determined by TFA hydrolysis and derivatization of the released monosaccharides into their alditol acetates which were then separated and quantified by capillary GLC (Dawson et al., 1992).

\section{Results}

Fruit measurements. Normal ripening, as indicated by softening and increasing extractable juice levels, occurred in fruit that were ripened at $20 \mathrm{C}$ immediately after harvest, stored continuously at $0 \mathrm{C}$ for up to 4 weeks, or warmed intermittently during storage (Table 1). In contrast, fruit stored for 6 weeks at 0C ripened abnormally, having low extractable juice levels (Table 1) and a dry, grainy texture indicative of mealiness. Fruit stored continuously at $\mathrm{OC}$ softened only slightly during storage, while intermittently warmed fruit softened considerably during storage especially during the first warming treatment at 2 weeks as shown by the loss of firmness in the fruit removed from storage at 4 weeks (Table 1). Ripening for 6 days at 20C resulted in a loss of flesh firmness for all fruit, whether ripened immediately after harvest or ripened after storage, either continuous or with warming. Mealy fruit softened to a similar extent as fruit that ripened normally.

The extractable juice content of fruit was low during storage, whether continuous or with warming (Table 1). Ripening immediately after harvest resulted in a considerable increase in the extractable juice content, whereas mealy fruit showed no increase from levels during storage. Fruit stored with intermittent warming showed an increase in extractable juice levels during ripening but levels were lower than that of fruit ripened immediately after harvest.

Gel filtration chromatography-uronic acid-rich polymers Fruit at harvest contained PAW-soluble polymers that were heterogeneous with respect to $\mathrm{M}$, the major polymers having a high $\mathrm{M}_{\mathrm{r}}$ and eluting near the void volume (Fig. 1A). Throughout continuous storage, the $\mathrm{M}_{\mathrm{r}}$ of polymers decreased slightly from that at harvest (Fig. 1A). The initial intermittent warming treatment resulted in an increase in the amount of high $\mathrm{M}_{\mathrm{r}}$ polymer eluting near the void volume and intermediate $\mathrm{M}_{\mathrm{r}}$ polymers apparent when fruit were sampled at 4 weeks (Fig. 1B). After 6 weeks of storage with intermittent warming high $\mathrm{M}_{\mathrm{r}}$ polymers were no longer predominant. Ripening-associated changes either immediately after harvest and after 6 weeks of storage continuously or with intermittent warming are shown in Fig. 1C. After 6 days ripening immediately after harvest high $\mathrm{M}_{\mathrm{r}}$ polymers eluting near the void volume were considerably diminished with lower $\mathrm{M}_{\mathrm{r}}$ polymers becoming predominant (Fig. 1C). Fruit ripened after 6 weeks of continuous

Table 1. Flesh firmness and extractable juice content of nectarine mesocarp at harvest, after storage (either continuous or with intermittent warming) and after subsequent ripening. Values are the mean \pm standard error. Treatment numbers are as follows: 1, harvest; 2 , continuous storage for 2 weeks; 3 , continuous for 6 weeks 4 , continuous storage for 6 weeks and ripened at 20C for 6 days (mealy); 5 , storage for 4 weeks with warming at 20C for 2 days at 2 weeks; 6 , storage for 6 weeks with warming at 20C for 2 days at 2 and 4 weeks; 7 , as 6 . but also ripened at $20 \mathrm{C}$ for 6 days; 8 , after harvest and ripened at $20 \mathrm{C}$ for 6 days.

\begin{tabular}{lcc}
\hline \hline $\begin{array}{l}\text { Sampling } \\
\text { time }\end{array}$ & $\begin{array}{c}\text { Flesh firmness } \\
(\mathrm{N})\end{array}$ & $\begin{array}{r}\text { Extractable juice } \\
\text { content (ml/plug) }\end{array}$ \\
\hline 1 & $62 \pm 5$ & $0.52 \pm 0.03$ \\
2 & $63 \pm 3$ & $0.31 \pm 0.02$ \\
3 & $44 \pm 4$ & $0.32 \pm 0.02$ \\
4 & $9 \pm 2$ & $0.27 \pm 0.01$ \\
5 & $21 \pm 2$ & $0.33 \pm 0.02$ \\
6 & $18 \pm 2$ & $0.39 \pm 0.02$ \\
7 & $8 \pm 1$ & $0.53 \pm 0.0$ \\
8 & $7 \pm 1$ & $0.98 \pm 0.03$ \\
\hline
\end{tabular}




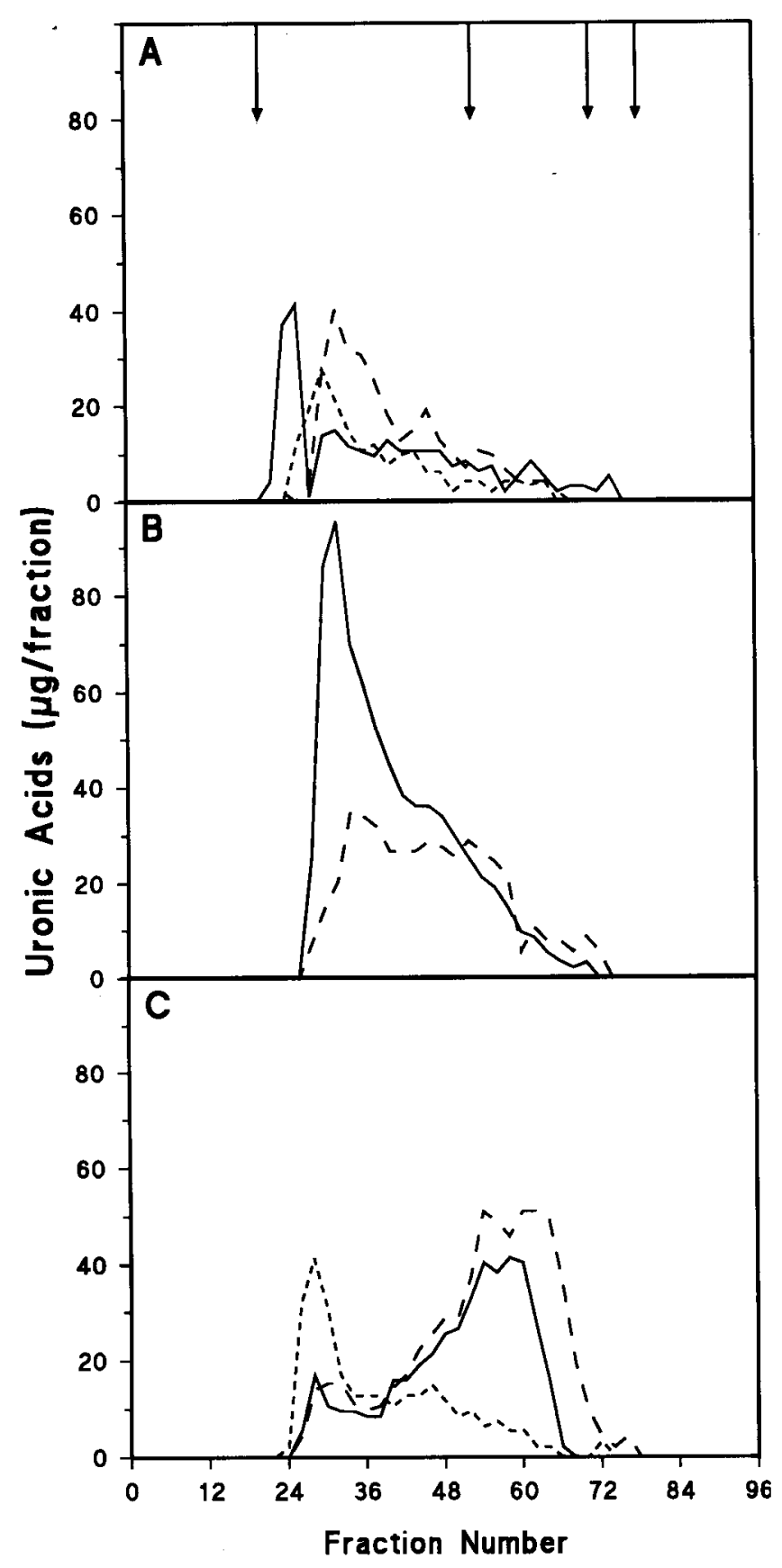

Fig. 1. Biogel A-50m filtration of PAW-soluble materials from nectarine tissue. Column fractions $(1.7 \mathrm{ml})$ were assayed for uronic acid using the $m$-hydroxydiphenyl method (Blumenkrantz and Asboe-Hansen, 1973). The arrows represent, from left to right, the void volume and dextran molecular weight markers of $\mathrm{M}_{\mathrm{r}} 2 \times 10^{6}$, $5 \times 10^{5}$, and $4 \times 10^{4}$. (A) At harvest (-), storage after 2 weeks at $0 \mathrm{C}(---)$ and after 6 weeks at $0 \mathrm{C}(---)$, without a ripening period. (B) Storage after 4 weeks at $0 \mathrm{C}$ with $2 \mathrm{~d}$ at $20 \mathrm{C}$ at 2 weeks (-) and after 6 weeks at $0 \mathrm{C}$ with 2 days at $20 \mathrm{C}$ at 2 and 4 weeks (---), without a ripening period. (C) After 6 days ripening at 20C without storage (normal ripening) (-), with storage at $0 \mathrm{C}$ for 6 weeks (mealy fruit) (- - ) and with storage at 0C for 6 weeks, interupted for 2days at $20 \mathrm{C}$ at 2 and 4 weeks storage (intermittently warmed fruit) (- - -).

storage showed essentially the same $\mathrm{M}_{\mathrm{r}}$ profile as fruit at harvest. Ripening of fruit for 6 days at 20C after 2 and 4 weeks of storage resulted in loss of high $\mathrm{M}_{\mathrm{r}}$ polymers and an increase in lower $\mathrm{M}_{\mathrm{r}}$ species (data not shown), similar to that observed for normal ripening. Fruit ripened after 6 weeks of storage with intermittent warming contained predominantly intermediate and low $\mathrm{M}_{\mathrm{r}}$ polymers (Fig. 1C). Fruit ripened after 4 weeks of storage (data not

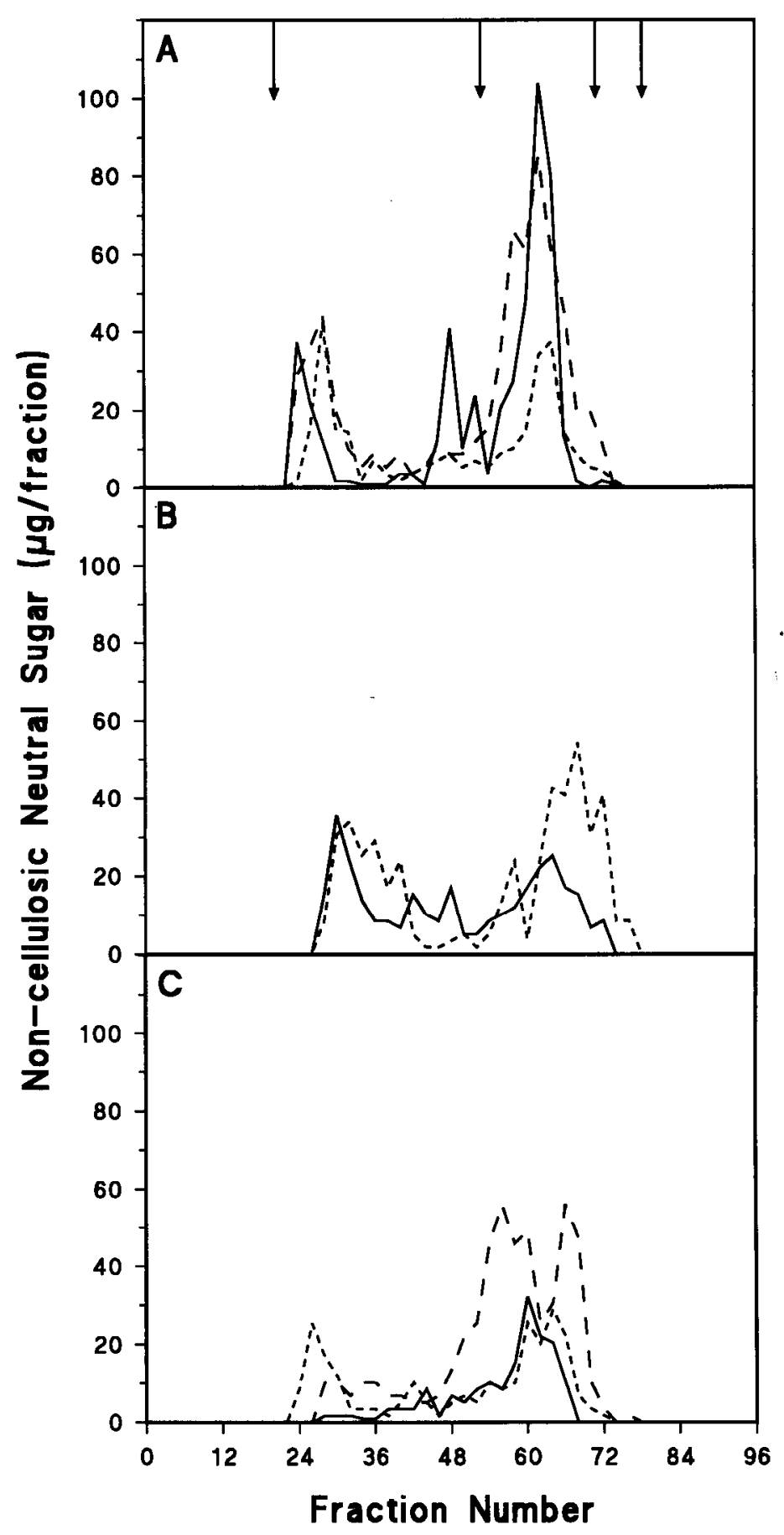

Fig. 2. Biogel A-50m filtration of PAW-soluble materials from nectarine tissue. Column fractions $(1.7 \mathrm{ml})$ were assayed for neutral sugars using the anthrone method (Dische, 1962). The arrows represent, from left to right, the void volume and dextran molecular weight markers of M $2 \times 10^{6}, 5 \times 10^{5}$, and $4 \times 10^{4}$. (A) At

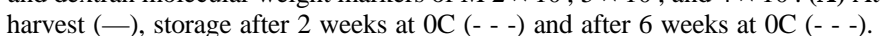
(B) Storage after 4 weeks at $0 \mathrm{C}$ with 2 days at $20 \mathrm{C}$ at 2 weeks (-) and after 6 weeks at $0 \mathrm{C}$ with 2 days at $20 \mathrm{C}$ at 2 and 4 weeks (- - ). (C) After 6 days ripening at $20 \mathrm{C}$ (normal ripening) (-), for mealy fruit (- - -) and for fruit ripened after 6 weeks storage at $0 \mathrm{C}$ with 2 days at $20 \mathrm{C}$ at 2 and 4 weeks storage followed by 6 days ripening at $20 \mathrm{C}(---)$.

shown) that had been subjected to a single warming treatment had a similar $M_{r}$ profile to that of fruit after 6 weeks of storage also with intermittent warming.

Neutral sugar-rich polymers. Fruit at harvest contained predominantly low $\mathrm{M}_{\mathrm{r}} \mathrm{PAW}$-soluble neutral sugar-rich polymers eluting over fractions 58 to 64 with lesser amounts of high and 
Table 2. Neutral sugar composition and uronic acid content of the PAW-soluble material from nectarine mesocarp at harvest, during storage, either continuous or with intermittent warming, and subsequent ripening. Treatment numbers are as follows: 1, harvest; 2 , continuous storage for 2 weeks; 3, continuous storage for 6 weeks; 4 , continuous storage for 6 weeks and ripened at 20C for 6 days (mealy); 5, storage for 4 weeks with warming at 20C for 2 days at 2 weeks; 6 , storage for 6 weeks with warming at $20 \mathrm{C}$ for 2 days at 2 and 4 weeks; 7 , as 6 . but also ripened at 20C for 6 days; 8 , after harvest and ripened at $20 \mathrm{C}$ for 6 days.

\begin{tabular}{lccccrcc}
\hline \hline $\begin{array}{l}\text { Treatment } \\
\text { no. }\end{array}$ & Rha & Ara & Xyl & Gal & Glc & . Uronic $\begin{array}{c}\text { Yield } \\
\text { acid }(\%)\end{array}$ \\
\cline { 2 - 6 }$(\mathrm{mg} / 100 \mathrm{~g} \mathrm{FW})$
\end{tabular}

${ }^{2}$ Anhydro-values after TFA hydrolysis. Values are the mean of duplicate analyses and for any value the error is <10\%.

intermediate $\mathrm{M}_{\mathrm{r}}$ polymers (Fig. 2A). During continuous storage at $0 \mathrm{C}$ some decrease in intermediate and low $M_{r}$ neutral polymers occurred (Fig. 2A). Throughout storage, fruit subject to intermittent warming showed a slight downshift in high and low $\mathrm{M}_{\mathrm{r}}$ polymers (Fig. 2B). During normal ripening the amount of high $\mathrm{M}_{\mathrm{y}}$ neutral sugar-rich polymers decreased whereas material from mealy fruit contained high $\mathrm{M}_{\mathrm{r}}$, polymers eluting at the void volume and a broad band of low $M_{r}$ polymers in fractions 56 to 68 . Fruit ripened after 6 weeks of storage that had been subjected to intermittent warming during storage had a profile similar to that of normally ripened fruit, the predominant polymers being low $\mathrm{M}_{\mathrm{r}}$.

Composition of the PAW-soluble and CWM-PAW-soluble material. Continuous storage at $0 \mathrm{C}$ for up to 6 weeks resulted in no change in the uronic acid content while arabinosyl, xylosyl and galactosyl residue levels were slightly higher than at harvest and glucosyl residue contents were lower (Table 2). A considerable increase in PAW-soluble uronic acid occurred after the first warming treatment during storage (Table 2). Rhamnosyl and arabinosyl levels also increased after the first warming treatment but to greater extent than found during continuous storage at $0 \mathrm{C}$, and did not change appreciably thereafter. Ripening of fruit immediately after harvest was associated with a considerable increase in the uronic acid content of the PAW-soluble fraction (Table 2). Arabinosyl residues were the major neutral sugar present at harvest and increased during ripening as did xylosyl residues, whereas glucosyl residue levels decreased. Fruit ripened after 2 and 4 weeks of continuous storage ripened normally and had similar PAW-soluble compositions to that from ripe fruit (data not shown). Mealy fruit, ripened after 6 weeks of continuous storage at $0 \mathrm{C}$, showed an increase in uronic acid in the PAW-soluble material compared to fruit at removal from storage. Neutral sugars, with the exception of xylosyl, galactosyl, and glucosyl residues remained at levels similar to harvest. Fruit ripened after intermittent warming treatments appeared to ripened normally. The uronic acid content and neutral sugar composition of the PAW-soluble material from fruit after 6 weeks of storage with intermittent warming and after subsequent ripening were similar.

$C W M$. Fruit stored continuously at $0 \mathrm{C}$ retained a high CWM uronic acid content, similar to that of harvest fruit (Table 3). The neutral sugar composition also remained similar to that of CWM of harvest fruit, except for the decrease in galactosyl residue levels during storage (Table 3). The neutral sugar composition of the CWM during storage with intermittent warming, did not change appreciably from that at harvest, except arabinosyl and xylosyl residues which were present at levels similar to those of fruit ripened after harvest (Table 3). During normal ripening after harvest the uronic acid content of the CWM decreased by $57 \%$ (Table 3). Ripening resulted in only minor changes in the neutral sugar composition with a decrease in arabinosyl and an increase in xylosyl residue levels. Mealy fruit showed some loss of uronic acid from the CWM although not to the same extent as during normal

Table 3. Neutral sugar composition and uronic acid content of the CWM from nectarine mesocarp at harvest, during storage, either continuous or with intermittent warming, and subsequent ripening. Treatment numbers are as follows: $1=$ harvest; $2=$ continuous storage for 2 weeks; 3 = continuous storage for 6 weeks; $4=$ continuous storage for 6 weeks and ripened at 20C for 6 days (mealy); $5=$ storage for 4 weeks with warming at $20 \mathrm{C}$ for 2 days at 2 weeks; $6=$ storage for 6 weeks with warming at $20 \mathrm{C}$ for 2 days at 2 and 4 weeks; $7=$ as 6 , but also ripened at 20C for 6 days; $8=$ after harvest and ripened at $20 \mathrm{C}$ for 6 days.

\begin{tabular}{lccccccc}
\hline \hline $\begin{array}{l}\text { Treatment } \\
\text { no. }\end{array}$ & Rha & Ara & Xyl & Gal & Glc & Uronic $\begin{array}{c}\text { Yield } \\
\text { acid }(\%)\end{array}$ \\
\cline { 2 - 5 }$(\mathrm{mg} / 100 \mathrm{~g} \mathrm{FW})$
\end{tabular}

${ }^{2}$ Anhydro-values after TFA hydrolysis. Values are the mean of duplicate analyses and for any value the error is $<10 \%$. 
Table 4. Neutral sugar composition and uronic acid content of the CDTA-soluble fraction from nectarine mesocarp at harvest, during storage, either continuous or with intermittent warming, and subsequent ripening. Treatment numbers are as follows: 1 , harvest; 2, continuous storage for 2 weeks; 3 , continuous storage for 6 weeks ; 4, continuous storage for 6 weeks and ripened at 20C for 6 days (mealy); 5, storage for 4 weeks with warming at 20C for 2 days at 2 weeks; 6 , storage for 6 weeks with warming at $20 \mathrm{C}$ for 2 days at 2 and 4 weeks; 7 , as 6 . but also ripened at 20C for 6 days; 8 , after harvest and ripened at 20C for 6 days.

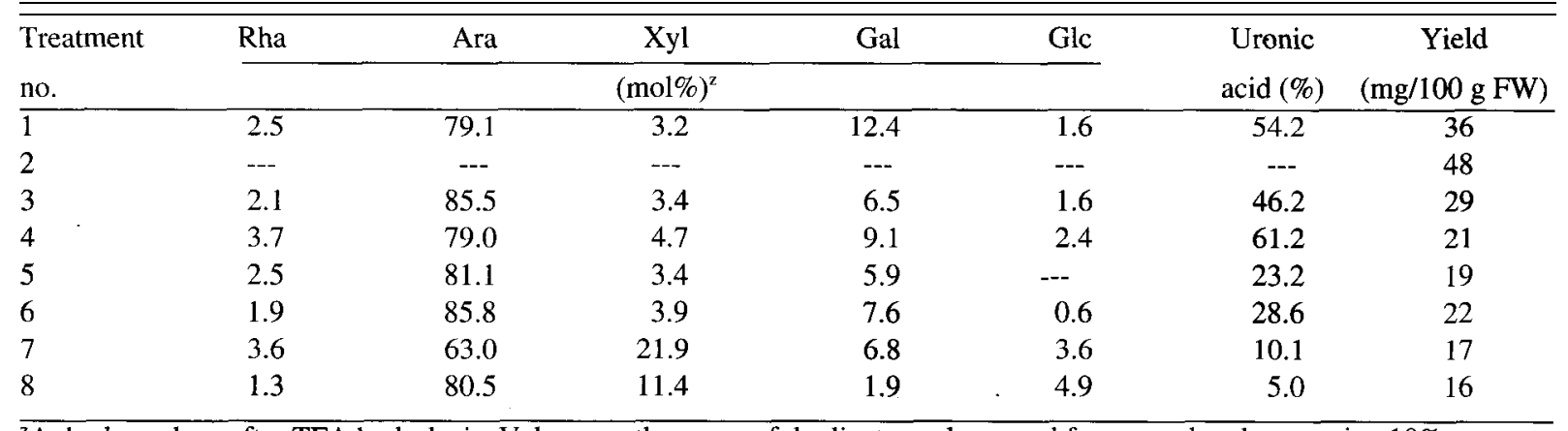

${ }_{7}^{7}$ Anhydro values after TFA hydrolysis. Values are the mean of duplicate analyses and for any value the error is $<10 \%$.

ripening (Table 3). The neutral sugar composition of CWM from mealy fruit was similar to that of normally ripened fruit. Ripening after intermittent warming resulted in no further change in the uronic acid content of the CWM. However, the neutral sugar composition of fruit ripened after intermittent warming was considerably altered with major loss of arabinosyl and increases in xylosyl and galactosyl residue levels.

Composition of the fractionated CWM. CDTA-soluble fraction: The neutral sugar composition of the CDTA-soluble fraction of fruit throughout continuous storage at $0 \mathrm{C}$ did not change appreciably from that of fruit at harvest, with the exception of galactosyl residues and the uronic acid content, which decreased over the 6-week storage period (Table 4). Intermittent warming of fruit during storage resulted in considerable loss of uronic acid from the CDTA-soluble fraction, most dramatically during the initial warming treatment at 2-week. A considerable loss of uronic acid from the CDTA-soluble fraction during normal ripening accounted for most of the decrease in yield observed between harvest and day 6 of normal ripening (Table 4). Arabinosyl residues were the major neutral sugar present and did not change during normal ripening although loss of galactosyl and an increase in xylosyl residues was observed during this period. In mealy fruit the uronic acid content of the CDTA-soluble fraction was increased from that at removal from storage while little change in neutral sugar composition occurred. Ripening of intermittently warmed fruit resulted in a further decrease in the uronic acid content of the CDTA-soluble fraction, to levels comparable to day 6 of normal ripening while arabinosyl residue levels markedly decreased and xylosyl levels increased to be greater than at any other stage of ripening and/or storage.

$\mathrm{Na}_{2} \mathrm{C} \mathrm{O}_{3}$-soluble fraction: During continuous storage at $0 \mathrm{C}$ there was no change in the uronic acid content or neutral sugar composition of the $\mathrm{Na}_{2} \mathrm{CO}_{3}$-soluble fraction except for a decrease ingalactosyl residues (Table 5). Intermittent warming of fruit during storage resulted in a gradual loss of uronic acid and arabinose from the $\mathrm{Na}_{2} \mathrm{CO}_{3}$-soluble fraction while xylosyl residues accumulated. Normal ripening, from harvest to day 6, resulted in a decrease in the amount of uronic acid for although the \% uronic acid not vary, the yield decreased by $50 \%$ (Table 5). The uronic acid content of the $\mathrm{Na}_{2} \mathrm{CO}_{3}$-soluble fraction from mealy fruit was unchanged from that at removal from storage (Table 5). Mealy fruit rhamnosyl levels were elevated relative to normal ripening, with other sugars being present at levels similar to day 6 of normal ripening. Ripening after storage with intermittent warming resulted in further loss of uronic acid from levels at removal from storage, similarly further loss of arabinosyl residues was seen during the ripening period. Rhamnosyl residues, which accumulated during storage with intermittent warming, decreased during the ripening period while xylosyl and galactosyl residue levels increased further during ripening.

Table 5. Neutral sugar composition and uronic acid content of the $\mathrm{Na}_{2} \mathrm{CO}_{3}$-soluble fraction from nectarine mesocarp at harvest, during storage, either continuous or with intermittent warming, and subsequent ripening. Treatment numbers are as follows: $1=$ harvest; 2 = continuous storage for 2 weeks; 3 = continuous storage for 6 weeks; 4 , continuous storage for 6 weeks and ripened at $20 \mathrm{C}$ for 6 days (mealy); $5=$ storage for 4 weeks with warming at $20 \mathrm{C}$ for 2 days at 2 weeks; $6=$ storage for 6 weeks with warming at $20 \mathrm{C}$ for 2 days at 2 and 4 weeks; $7=$ as 6 , but also ripened at $20 \mathrm{C}$ for 6 days; $8=$ after harvest and ripened at $20 \mathrm{C}$ for 6 days.

\begin{tabular}{|c|c|c|c|c|c|c|c|}
\hline Treatment & Rha & Ara & Xyl & Gal & Glc & \multirow{2}{*}{$\begin{array}{l}\text { Uronic } \\
\text { acid }(\%)\end{array}$} & \multirow{2}{*}{$\begin{array}{c}\text { Yield } \\
(\mathrm{mg} / 100 \mathrm{~g} \mathrm{FW})\end{array}$} \\
\hline no. & \multicolumn{5}{|c|}{$(\mathrm{mol} \%)^{z}$} & & \\
\hline$\overline{1}$ & 3.5 & 83.5 & 1.9 & 10.1 & 0.5 & 37.8 & 25 \\
\hline 2 & 2.5 & 83.5 & 1.4 & 11.9 & 2.9 & 46.3 & 22 \\
\hline 3 & 2.5 & 86.0 & 2.4 & 5.5 & 2.9 & 39.4 & 20 \\
\hline 4 & 4.8 & 79.7 & 3.6 & 10.2 & 1.8 & 39.0 & 20 \\
\hline 5 & 7.8 & 81.2 & 1.3 & 9.5 & 0.3 & 46.6 & 14 \\
\hline 6 & 8.5 & 76.3 & 6.0 & 9.3 & $\mathrm{tr}^{\mathrm{y}}$ & 39.3 & 15 \\
\hline 7 & 3.0 & 67.2 & 10.3 & 14.2 & 3.7 & 27.9 & 8 \\
\hline 8 & 3.2 & 81.3 & 3.4 & 10.2 & 0.8 & 40.0 & 12 \\
\hline
\end{tabular}

${ }^{{ }^{z}}$ Anhydro-values after TFA hydrolysis. Values are the mean of duplicate analyses and for any value the error is $<10 \%$. 


\section{Discussion}

'Fantasia' nectarines ripened after 6 weeks of storage at 0C were mealy. In contrast, fruit subject to intermittent warming during storage were juicy and appeared to-ripened normally after storage. The prevention of mealiness by intermittent warming was consistent with previous findings (Anderson, 1979; Anderson and Penny, 1975; Ben-Arie and Sonego, 1980; Ben-Arie et al., 1970; Buescher and Furmanski, 1978; Lill, 1985). Our study indicates that intermittent warming during storage appears to promote ripening, and that cell wall compositional changes observed in this study during intermittent warming correlate with the early stages of normal ripening (Dawson et al., 1992). Consequently, intermittently warmed fruit removed from storage after 6 weeks appear to be at the midpoint in the normal ripening process as evidenced by fruit softening and cell wall compositional data. After the 6-day ripening period, the cell wall composition and the depolymerization of the pectic and neutral wall-polysaccharides was similar to, but not identical to, fruit that had been ripened without storage. A slight downshift in high $\mathrm{M}_{\mathrm{r}}$ polyuronate occurred during storage while most degradation occurred during the 6-day ripening period. Greatest softening occurred during intermittent warming, from which we can conclude that depolymerization of pectic polymers did not appear to contribute to the softening process. While there were changes in the uronic acid and neutral sugar composition in the pectic cell wall polymers as a result of intermittent warming, the large decrease in the $\mathrm{M}_{\mathrm{r}}$ values of the water-soluble pectic polymers (Figs. 1 and 2) occurred during ripening. It appears that intermittent warming alleviates mealiness by promoting pectic polymer solubilization, the immediate effect being loss of flesh firmness. Solubilization of pectic polymers from the wall is a complex process and in fruit subject to intermittent warming solubilization appears to involve the action of polygalacturonase as well as removal of pectic polymer neutral sugar side chains as evidenced by the decrease in arabinose.

Cell wall composition of mealy nectarines was distinctly different than normal fruit. There appeared to have been some limited solubilization of pectic substances from mealy fruit CWM although solubilization was not as extensive as fruit undergoing normal ripening. The solubilized uronic acid-rich polymers were of high $\mathrm{M}_{\mathrm{r}}$ and were not depolymerized during the ripening period, similar to results we have previously reported (Dawson et al., 1992), but contrary to the results of Lurie et al. (1994) for a water-soluble fraction from 'Fiesta Red' nectarines. Our results support the hypothesis that polygalacturonase was partially inactivated during extended continuous cool storage. However, polygalacturonic acid is not the only cell wall polysaccharide affected by the mealiness disorder. The degradation of the pectic polysaccharide galactan is reduced $\mathrm{co}_{\mathrm{m}}$ pared to normal ripening as evidenced by an increase in galactosyl residues in the CDTA and $\mathrm{Na}_{2} \mathrm{CO}_{3}$ fractions of mealy fruit. The arabinosyl content of the water-soluble (PAW-soluble) fraction from mealy 'Fantasia' nectarines was considerably lower compared to that of normal ripe fruit. Lurie et al. (1994) have also reported lower arabinosyl levels in the cell walls of mealy 'Fiesta Red' nectarines compared to normal ripe fruit, albeit in the CDTA- and $\mathrm{Na}_{2} \mathrm{C} \mathrm{O}_{3}$-soluble fractions and not in the water-soluble fraction. The lack of precise agreement on which pectic fractions show changes in arabinosyl residues may be due to different procedures or cultivars used in the two investigations. Nevertheless, both studies suggest enhanced degradation of pectic arabinan side-chains in mealy fruit.
It is apparent from our work and related studies together with electrical measurements (Furman\&i and Buescher, 1979; Harker and Maindonald, 1994) that mealiness in nectarines is a physiological disorder involving the cell walls. If polygalacturonase is irreversibly inhibited during prolonged continuous cold storage, the undegraded pectic polymers could form a calcium-pectate gel, resulting in the increased electrical resistance observed by Harker and Maindonald. The calcium-pectate gel might then bind water and produce the apparent dryness associated with mealiness.

\section{Literature Cited}

Anderson, R.E. 1979. The influence of storage temperature and warming during storage on peach and nectarine fruit quality. J. Amer. Soc. Hort. Sci. 104:459-461.

Anderson, R.E. and R.W. Penney. 1975. Intermittent warming of peaches and nectarines stored in a controlled atmosphere or air. J. Amer. Soc. Hort. Sci. 100:151-153.

Ben-Arie, R. and S. Lavee. 1971. Pectic changes occurring in 'Elberta' peaches suffering from woolly breakdown. Phytochemistry 10:531538.

Ben-Arie, R., S. Lavee, and S. Guelfat-Reich. 1970. Control of woolly breakdown of 'Elberta' peaches in cold storage by intermittent exposure to room temperature. J. Amer. Soc. Hort. Sci. 95:801-803.

Ben-Arie, R. and L. Sonego. 1980. Pectolytic enzyme activity involved in woolly breakdown of stored peaches. Phytochemistry 19:2553-2555.

Blumenkrantz, N. and G. Asboe-Hansen. 1973. New method of quantitative determination of uronic acids. Anal. Biochem. 54:484-489.

Buescher, R.W. and R.J. Furmanski. 1978. Role of pectinesterase and polygalacturonase in tbe formation of woolliness in peaches. J. Food. Sci. 43:264-266.

Dawson, D.M., L.D. Melton, and C.B. Watkins. 1992. Cell wall changes in nectarines (Prunus persica): Solubilization and depolymerization of pectic and neutral polymers during ripening and in mealy fruit. Plant Physiol. 100:1203-1210; 102:1062-1063.

Dawson, D.M., C.B. Watkins, and L.D. Melton. 1993. Calcium uptake efflux, ion leakage, internal air space and cation exchange capacity in relation to mealiness in nectarine tissue. Postharvest Biol. Technol. 3:131-141.

Dische, Z. 1962. Colour reactions of carbohydrates. p. 475-514. In: R.L. Whistler and M.L. Wolfrom (eds.). Methods in Carbohydrate Chemistry. Academic Press, New York.

Furmanski, R.J. and R.W. Buescher. 1979. Influence of chilling on electrolyte leakage and internal conductivity of peach fruits. HortScience 14:167-168.

Gross, K.C. and C.E. Sams. 1984. Changes in cell wall neutral sugar composition during fruit ripening: a species survey. Phytochemistry 23:2457-2461.

Harker, F.R. and J.H. Maindonald. 1994. Ripening of nectarine fruit: Changes in the cell wall, vacuole and membranes detected using electrical impedance measurements. Plant Physiol. 106:165-171.

Jarvis, M.C. 1982. The proportion of calcium-bound pectin in plant cell walls. Planta 154:344-346.

Kintner, P.K. and J.P. Van Buren. 1982. Carbohydrateinterference and its correction in pectin analysis using the $m$-hydroxydiphenyl method. J. Food Sci. 47:756-764.

Lill, R.E. 1985. Alleviation of internal breakdown of nectarines during cold storage by intermittent warming. Scientia Hort. 25:241-246.

Lill, R.E. and G.J. Van Der Mespel. 1988. A method for measuring the juice content of mealy nectarines. Scientia Hort. 36:267-271.

Lurie, S., A. Levin, L.C. Greve, and J.M. Labavitch. 1994. Pectic polymer changes in nectarines during normal and abnormal ripening. Phytochemistry 36: 11-17.

Pressey, R., D.M. Hinton, and J.K. Avants. 1971. Development of polygalacturonase activity and solubilization of pectin in peaches during ripening. J. Food Sci. 36:1070-1073. 